\title{
Antimicrobial Activity of Cerium Oxide Nanoparticles on Opportunistic Microorganisms: A Systematic Review
}

\author{
Isabela Albuquerque Passos Farias (iD, Carlos Christiano Lima dos Santos, \\ and Fábio Correia Sampaio
}

Science Center of Health, Federal University of Paraíba, 58.051-900 João Pessoa, PB, Brazil
Correspondence should be addressed to Isabela Albuquerque Passos Farias; isapassosfarias@gmail.com

Received 19 September 2017; Accepted 13 December 2017; Published 23 January 2018

Academic Editor: Jinsong Ren

Copyright (c) 2018 Isabela Albuquerque Passos Farias et al. This is an open access article distributed under the Creative Commons Attribution License, which permits unrestricted use, distribution, and reproduction in any medium, provided the original work is properly cited.

\begin{abstract}
An evaluation of studies of biologically active nanoparticles provides guidance for the synthesis of nanoparticles with the goal of developing new antibiotics/antifungals to combat microbial resistance. This review article focuses on the physicochemical properties of cerium oxide nanoparticles (CeNPs) with antimicrobial activity. Method. This systematic review followed the Guidelines for Transparent Reporting of Systematic Reviews and Meta-Analyses. Results. Studies have confirmed the antimicrobial activity of CeNPs (synthesized by different routes) using nitrate or chloride salt precursors and having sizes less than $54 \mathrm{~nm}$. Conclusion. Due to the lack of standardization in studies with respect to the bacteria and CeNP concentrations assayed, comparisons between studies to determine more effective routes of synthesis are difficult. The mechanism of CeNP action likely occurs through oxidative stress of components in the cell membrane of the microorganism. During this process, a valence change occurs on the CeNP surface in which an electron is gained and $\mathrm{Ce}^{4+}$ is converted to $\mathrm{Ce}^{3+}$.
\end{abstract}

\section{Introduction}

The prevalence of health care-associated infections is high, especially those of blood and urinary tract infections that are associated with catheters and surgical site infections [1].

Microorganisms responsible for such infections include, in order of decreasing frequency, Staphylococcus aureus, Enterococcus spp., and Escherichia coli. Resistant microorganisms are present in $20 \%$ of infections, especially methicillinresistant Staphylococcus aureus (MRSA) [1].

The yeast Candida albicans is the species most commonly involved in fungal infections [2]. Candida albicans is a dimorphic and commensal fungus that colonizes the skin, gastrointestinal tract, and reproductive system [3]. The number of new cases of fungal infections in immunocompromised patients is increasing throughout the world $[4,5]$.

The use of nanotechnology to develop nanoscale materials having antimicrobial activities has been proposed for the development of new therapeutic products and effective strategies for prophylaxis and treatment of infections [6-8]. Recently, nanomaterials exhibited a great potential as contrast agents for visualizing the gastrointestinal tract [9] and nanofibers have also been used as carriers for nanoparticles that can interfere in multidrug resistant bacteria infections [10].

In comparison with small molecule antimicrobial agents, which have short-term activity and are often environmentally toxic, nanoparticulate agents with antimicrobial effects exhibit prolonged effects and are minimally toxic [8]. In addition, Escherichia coli bacteria growth inhibition has been shown to be inversely proportional to the size of the nanoparticles [11].

Among these agents, the nanoparticulate cerium dioxide (CeNP) is a rare earth metal oxide of the cubic fluorite type $[12,13]$ and is of great interest because of its optical and electronic properties. It has extensive industrial applications in medicine, catalysis, and optical and sensor technologies [14]. Its properties are related to its valence, since cerium 


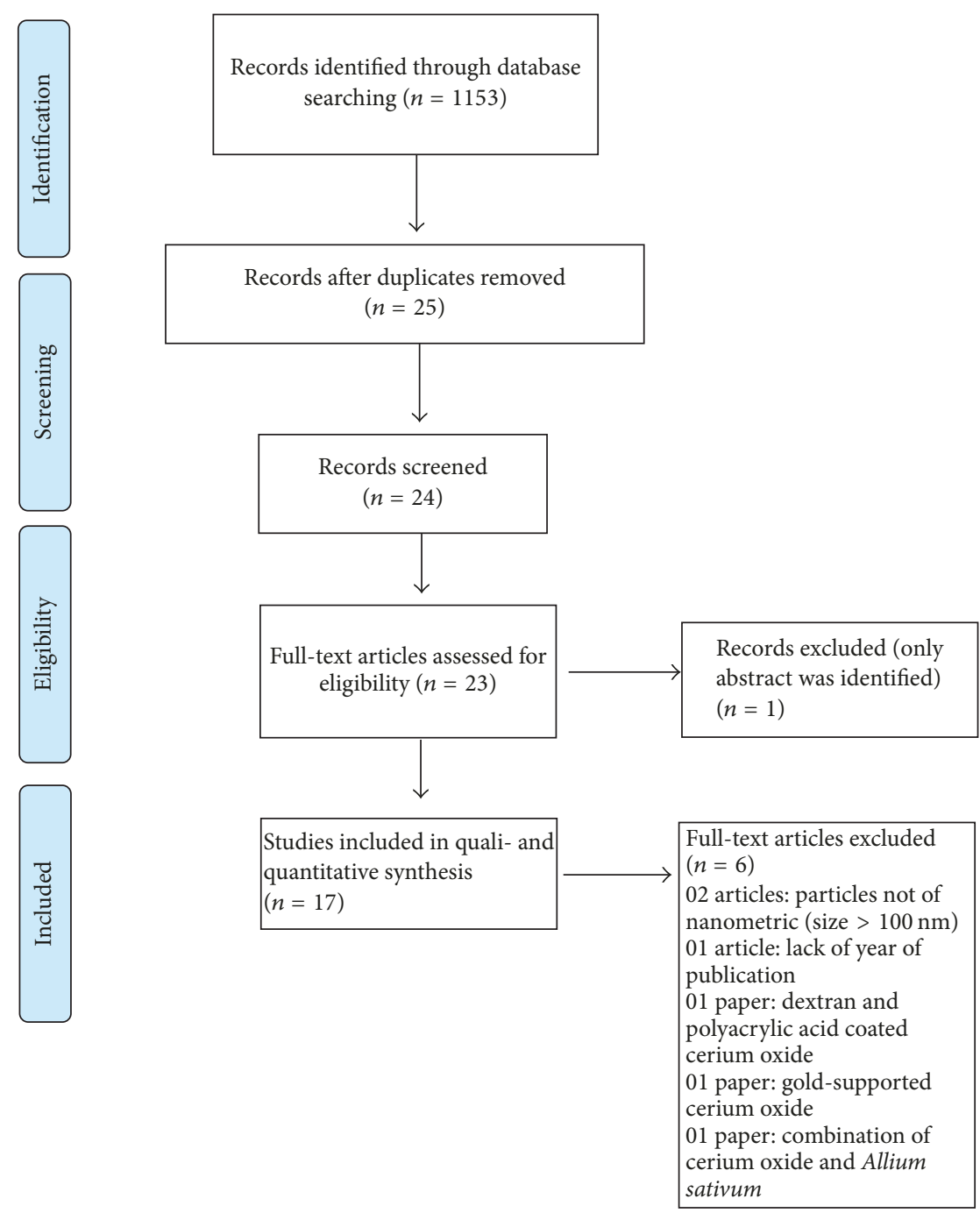

FIGURE 1: Flow diagram of the search strategy used to identify studies included in this review based on PRISMA guidelines [19].

is the only stable tetravalent state lanthanide, whereas other lanthanides are only stable in the trivalent state [15].

Natural sources of nanoparticles include soil erosion, water evaporation sprays, and plants [16]. In industry, cerium metal is present in sunscreen, solid electrolytes, solar cells, fuel cells, luminescence, photocatalysts, and sensors [17]. Synthesis methodologies attempt to obtain small, highsurface-area particles to potentiate the chemical, physical, and antimicrobial properties of the nanoparticles.

The development of novel antimicrobial agents is of great interest due to the increase in the mortality rate associated with infection [18]. The goal of this systematic review is to address the physicochemical properties of cerium oxide nanoparticles having antimicrobial activity. The evaluation of biologically active nanoparticles provides guidance to nanoparticle synthesis with the aim of developing new antibiotics/antifungals to combat infection.

\section{Material and Methods}

This systematic review followed the Guidelines for Transparent Reporting of Systematic Reviews and Meta-Analyses (PRISMA statement) [19]. The systematic identification of articles was performed in five databases: Google Scholar, SciELO (Scientific Electronic Library Online), PubMed, Lilacs (Latin American and Caribbean Literature on Health Sciences), and Web of Science (Figure 1).

For the retrieval and selection of articles, the following keywords were used: cerium oxide, antimicrobial activity, antifungal activity, bacterial activity, toxicity, and nanoparticles.

All English, Spanish, and Portuguese articles related to the topic that were published from 2006 to October 27, 2016, were selected for analysis. The final selection of articles was made using qualitative criteria in accordance with the 
theme of cerium oxide nanoparticulate antimicrobial activity. Initially, the titles and abstracts of the articles were assessed by two researchers. Only complete articles were included in the study.

Of the 24 studies identified, seven articles were excluded for the following reasons: the particles were not of nanometric (size $>100 \mathrm{~nm})(2$ articles), only the abstract was available ( 1 article), there was a lack of article data (such as year of publication) (1 article), dextran and polyacrylic acid-coated cerium oxide was utilized ( 1 article), gold-supported cerium oxide was utilized ( 1 article), and a combination of cerium oxide with Allium sativum was utilized (1 article). Thus, a total of 17 articles composed the final sample.

\section{Results and Discussion}

3.1. Cerium Oxide Nanoparticle: Synthesis and Physicochemical Characteristics. The materials used during nanoparticle synthesis influence the size and shape of the resulting nanocrystals. According to the in vitro studies analyzed in Table 1 , there are a variety of CeNP synthesis routes, with the predominant one using ammonium cerium as the precursor salt. Due to solubility, nitrate is preferable to other salts, and it also results in a homogeneous solution [17]. However, cerium chloride salt forms residual chlorine, which does not adversely affect biological systems and therefore is potentially the best precursor material for biological applications [15].

Of the 17 evaluated studies of CeNP antimicrobial activity (Table 1), seven used the principle of green chemistry with extracts of plants, fruits, and fungi [13, 14, 17, 20-23]. The green synthesis route is considered important because it is nontoxic and of low cost and decreases the use of substances that are harmful to human health and the environment [14, 22].

The morphology of the nanoparticles was determined by transmission electron microscopy (TEM) in the majority of studies (Table 1). The shapes of the particles observed through transmission electron microscopy were elliptical, spherical, square, oval, rectangular, triangular, and irregular. Microscopy was also used to evaluate the size of nanoparticles, which ranged from 5.0 [21] to $54 \mathrm{~nm}$ [13].

The average size of the CeNP crystallite was estimated by the Debye-Scherrer formula, as $58.82 \%(n=10)$ of the analyzed articles used this method. However, there are cases of divergence between these results and those observed using TEM. For example, a $24 \mathrm{~nm}$ size value calculated by the formula method was observed to be approximately $5 \mathrm{~nm}$ using TEM [21]. Regardless of the method, the analyzed studies highlighted the antimicrobial activity of nanoparticles at a particle size of less than $100 \mathrm{~nm}$ [24].

The Debye-Scherrer formula uses X-ray diffraction data, specifically the width at half-maximum of the diffraction peak $[15,17]$. The size of the nanoparticle can also be gauged by a formula that uses data from the Brunauer-Emmett-Teller (BET) equation, which considers the specific surface area and density of the nanoparticles [25].

$\mathrm{X}$-ray diffraction was used in studies to confirm the facecentered cubic crystalline structures. The absence of peaks from structures other than the nanoparticulate object of analysis indicates purity of the synthesis product [13].

Surface area is relevant because it is inversely proportional to the nanoparticle size $[26,27]$. Smaller crystal sizes and higher surface area lead to higher antibacterial activity. This physical characteristic was described in only three studies [28-30]. The smaller nanoparticles were those with the largest areas favoring a large catalysis surface area [26, 27].

The potential for CeNP catalysis is also influenced by the valence state of $\mathrm{Ce}^{4+}$ or $\mathrm{Ce}^{3+}$ [31]. This feature directly influences the anti- or prooxidant potential of CeNPs and determines different responses of the substrate to processes such as oxidative stress, superoxide radical cleaning, and hydrogen peroxide production. The conversion of $\mathrm{Ce}^{4+}$ to $\mathrm{Ce}^{3+}$ was observed in Escherichia coli [29], J774A.1 macrophage cells [31], and the hippocampus and cerebellum [32]. The surfaces of algae cells are protected against reactive oxygen species (ROS) in the face of low amounts of $\mathrm{Ce}^{3+}$ and high amounts of $\mathrm{Ce}^{4+}$. The autoregenerative mechanism of valence reversion influences the protective or toxic effect of the nanoparticle [33].

3.2. Studies of Cerium Oxide Nanoparticles against Opportunistic Microorganisms. The inhibitory activity of CeNP on microbial growth was studied in Gram-positive and Gram-negative planktonic bacterial cultures and biofilms. Microbiological tests used to test CeNP activity included enumeration of colony forming units (CFU), agar diffusion, time-kill, and cell viability using fluorescence assays (Tables 2-7).

Agar diffusion was the most frequently used to evaluate the sensitivity of $S$. aureus (Gram-positive) to CeNP, being used in 10 studies involving S. aureus (Table 2). The NCIM5022 strain was tested in three studies [17, 22, 30] and showed little sensitivity to CeNP (diffusion halos between 0.53 and $3.33 \mathrm{~mm}$ ). In contrast, another study [13] showed the formation of a $17 \mathrm{~mm}$ of halo, but information concerning the strain and nanoparticle concentration was omitted. For time-kill tests, a greater than $50 \%$ inhibition of the $S$. aureus at concentrations of $2.58-3.44 \mathrm{mg} / \mathrm{mL}$ [15] was observed. The two studies with the most significant antimicrobial activity results for $S$. aureus had cerium chloride as the CeNP precursor agent and a particle size of less than $54 \mathrm{~nm}$ in common (Tables 1 and 2).

The macrodilution test method detected a CeNP minimal inhibitory concentration (MIC) of $50 \pm 10 \mu \mathrm{g} / \mathrm{mL}$ using a planktonic culture of E. coli (Gram-negative) and $90 \pm 40 \mu \mathrm{g} / \mathrm{mL}$ for a biofilm; CeNP was sonicated prior

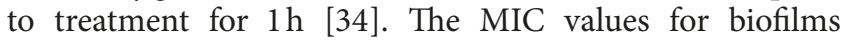
were superior to the planktonic culture, probably since the biofilm is more conducive to microorganism development. The benefits of antimicrobial nanoparticles have been suggested to be above and beyond other molecules because of their ability to penetrate biofilm substrates. Krishnamoorthy et al. [18] reported the lowest MIC of $16 \mu \mathrm{g} / \mathrm{mL}$ against $E$. coli for CeNP synthesized from cerium nitrate using sonochemical method and particles $\leq 25 \mathrm{~nm}$ in size (Table 1). 


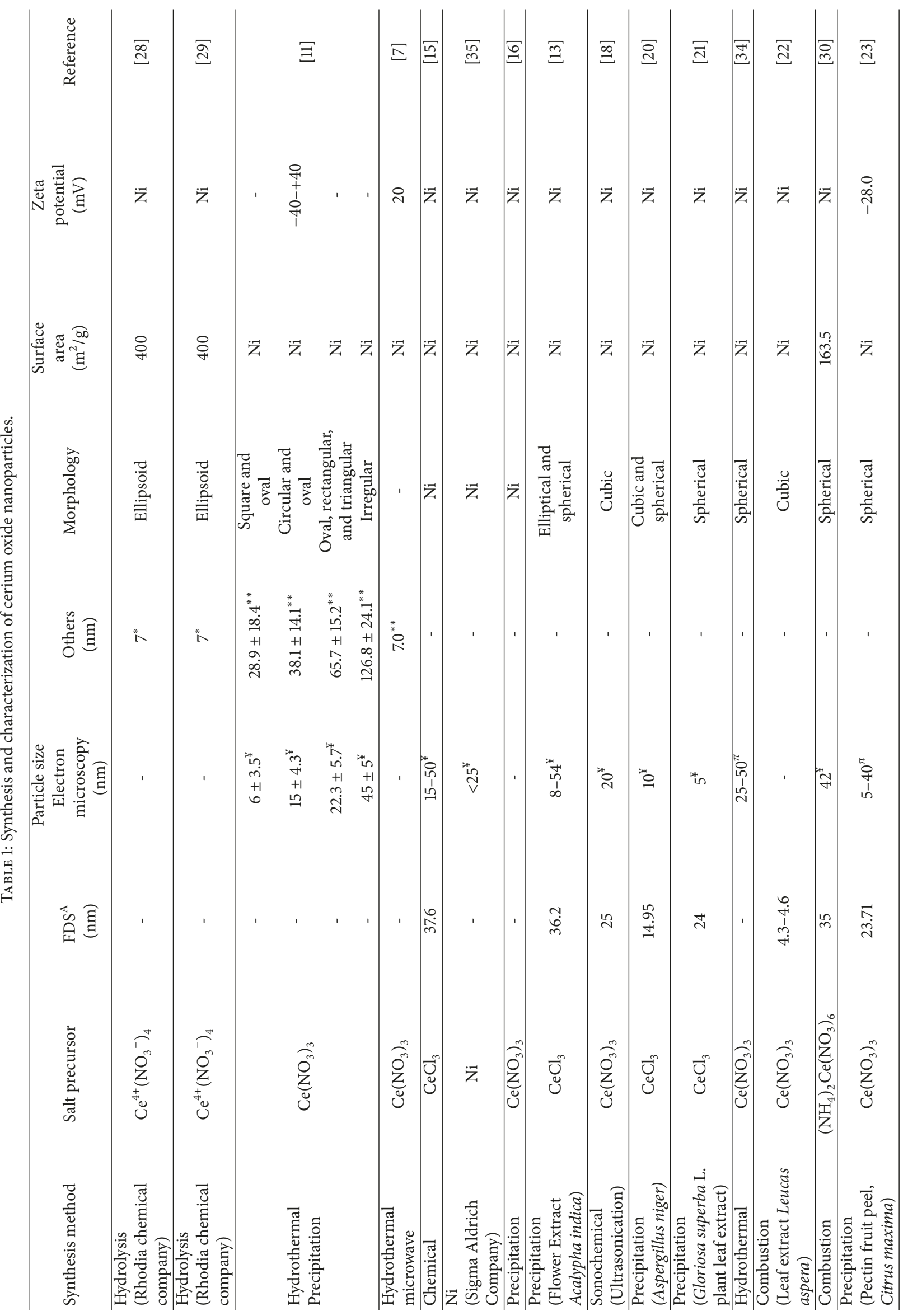




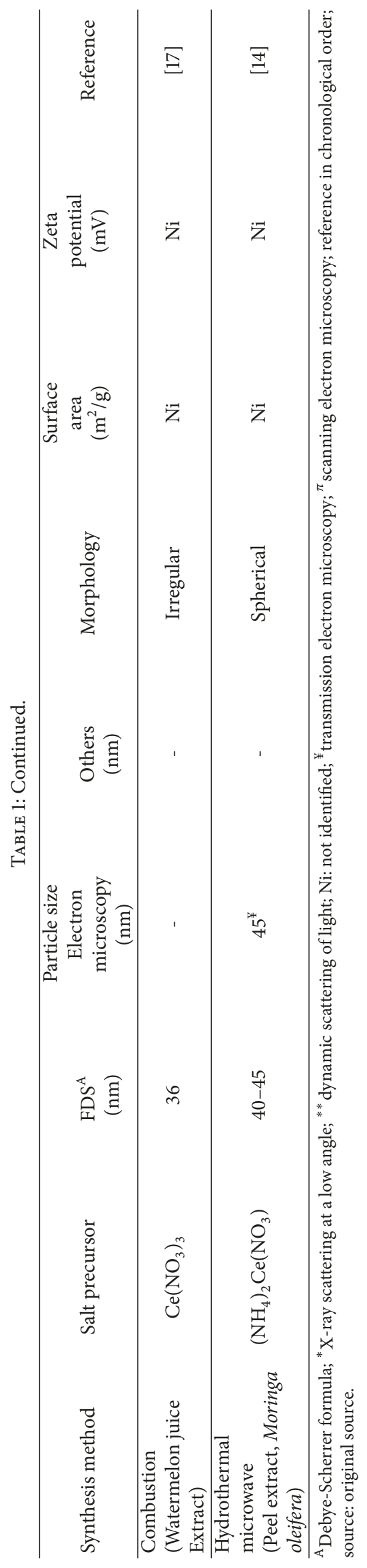




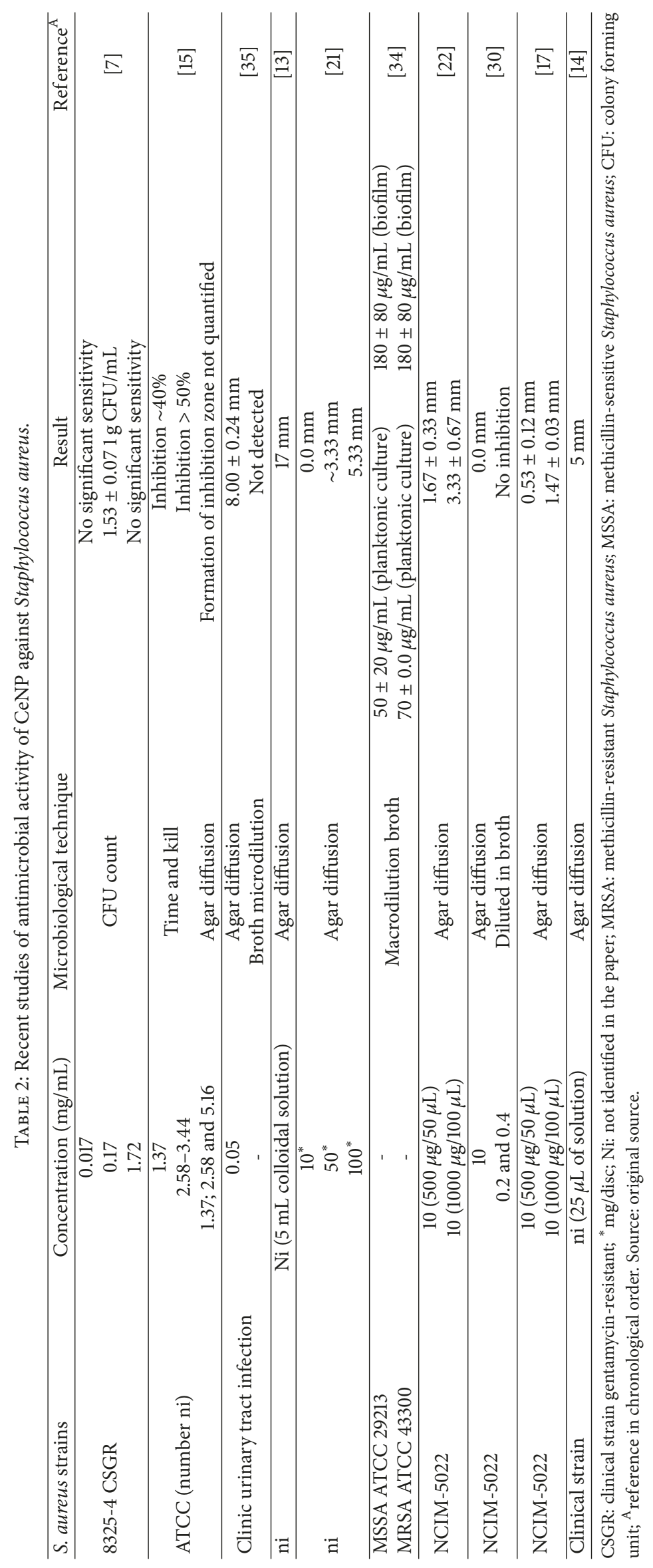




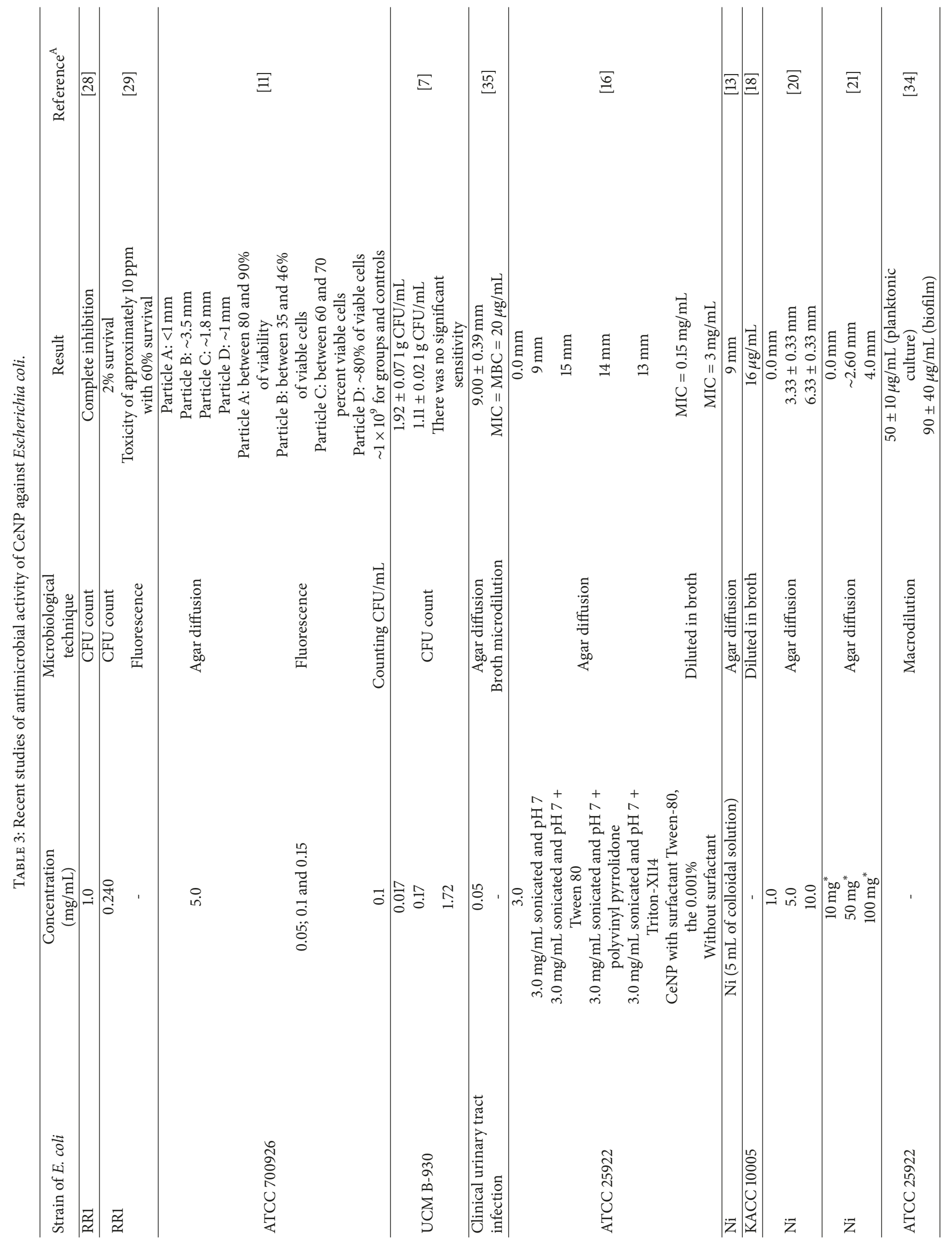




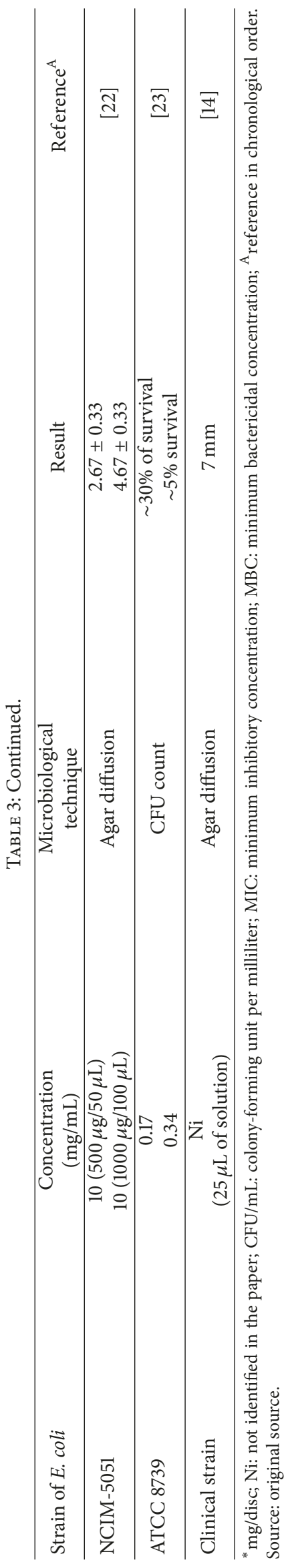


TABLE 4: Recent studies of CeNP antimicrobial activity against Pseudomonas aeruginosa.

\begin{tabular}{|c|c|c|c|c|}
\hline $\begin{array}{l}\text { Strain of } \\
\text { P. aeruginosa }\end{array}$ & $\begin{array}{l}\text { Concentration } \\
(\mathrm{mg} / \mathrm{mL})\end{array}$ & $\begin{array}{l}\text { Microbiological } \\
\text { technique }\end{array}$ & Result & Reference $^{A}$ \\
\hline \multirow{3}{*}{$\mathrm{Ni}$} & $10^{*}$ & & $0.0 \mathrm{~mm}$ & \multirow{3}{*}[21]{} \\
\hline & $50^{*}$ & Agar diffusion & $\sim 3 \mathrm{~mm}$ & \\
\hline & $100^{*}$ & & $4.67 \mathrm{~mm}$ & \\
\hline ATCC 27853 & - & Macrodilution & $\begin{array}{c}20 \pm 5 \mu \mathrm{g} / \mathrm{mL} \text { (planktonic culture) } \\
70 \pm 0.0 \mu \mathrm{g} / \mathrm{mL} \text { (biofilm) }\end{array}$ & {$[34]$} \\
\hline \multirow{4}{*}{ NCIM-2242 } & 10 & & $3.33 \mathrm{~mm}$ & \multirow{4}{*}[30]{} \\
\hline & 15 & Agar diffusion & $3.57 \mathrm{~mm}$ & \\
\hline & 20 & & $4.50 \mathrm{~mm}$ & \\
\hline & 0.2 and 0.4 & Diluted in broth & $\begin{array}{l}\text { Inhibition of growth was observed; } \\
\text { MIC was not identified }\end{array}$ & \\
\hline
\end{tabular}

${ }^{*} \mathrm{mg} /$ paper disk; ni: not identified in the paper; MIC:minimum inhibitory concentration; ${ }^{\mathrm{A}}$ reference in chronological order. Source: original source.

TABLE 5: Recent studies of CeNP antimicrobial activity against Bacillus subtilis.

\begin{tabular}{|c|c|c|c|c|}
\hline $\begin{array}{l}\text { Strain of } \\
\text { B. subtilis }\end{array}$ & $\begin{array}{l}\text { Concentration } \\
(\mathrm{mg} / \mathrm{mL})\end{array}$ & $\begin{array}{l}\text { Microbiological } \\
\text { technique }\end{array}$ & Result & Reference $^{\mathrm{A}}$ \\
\hline \multirow{3}{*}{ ATCC 6633} & 5.0 & Agar diffusion & $\begin{array}{l}\text { Particle A: } \sim 3.2 \mathrm{~mm} \\
\text { Particle B: }<1 \mathrm{~mm} \\
\text { Particle C: } \sim 2 \mathrm{~mm} \\
\text { Particle D: } \sim 3 \mathrm{~mm}\end{array}$ & \multirow{3}{*}[11]{} \\
\hline & $0.05 ; 0.1 ; 0.15$ & Fluorescence & $\begin{array}{c}\text { Particle A: between } 40 \text { and } 65 \% \text { of viable } \\
\text { cells } \\
\text { Particle B: between } 80 \text { and } 90 \% \text { of viable } \\
\text { cells } \\
\text { Particle C: between } 60 \text { and } 80 \% \text { viable } \\
\text { cells } \\
\text { Particle D: between } 45 \text { and } 65 \% \text { of viable } \\
\text { cells }\end{array}$ & \\
\hline & 0.1 & Counting CFU/mL & $\begin{array}{l}\text { Between } 10^{8} \text { and } 10^{9} \text { for experimental } \\
\text { groups and } 10^{9} \text { for control }\end{array}$ & \\
\hline KACC 14394 & - & $\begin{array}{c}\text { Broth } \\
\text { microdilution }\end{array}$ & $4 \mu \mathrm{g} / \mathrm{mL}$ & {$[18]$} \\
\hline \multirow{3}{*}{$\mathrm{Ni}$} & 1 & & $0.0 \mathrm{~mm}$ & \multirow{3}{*}[20]{} \\
\hline & 5 & Agar diffusion & $4.67 \pm 0.33 \mathrm{~mm}$ & \\
\hline & 10 & & $10.33 \pm 0.33 \mathrm{~mm}$ & \\
\hline ATCC 6633 & $\begin{array}{l}0.17 \\
0.34\end{array}$ & CFU count & $\begin{array}{l}\sim 40 \% \text { of survival } \\
\sim 12 \% \text { of survival }\end{array}$ & {$[23]$} \\
\hline
\end{tabular}

Ni: not identified in the paper; CFU: colony forming unit; ${ }^{A}$ reference in chronological order. Source: original source.

Sonication to avoid the formation of nanoparticle agglomerates is a relevant factor, as is the use of surfactants to form micelles around the nanoparticles. CeNPs made with Tween 80 , Triton X114, and polyvinylpyrrolidone surfactants at concentrations of 0.01 and $0.001 \%(\mathrm{p} / \mathrm{v})$ were tested for inhibition of $E$. coli. The lowest concentration observed with the highest sensitivity was $0.001 \%$ with Tween 80 , indicating the lowest required surfactant concentration for generating micelles around the nanoparticles [16]. In addition, it is believed that the surfactant changes the surface charge of CeNP, forming a complex with cerium, which is capable of filling the oxygen vacancy and thus prevents the antioxidant effect [16].

The antimicrobial activity of CeNP is concentration dependent [11, 15, 20]. Zeyons et al. [29] also observed this for E. coli by enumerating CFUs; however, the result was not dose dependent for the viability test using fluorescence. In the fluorescence assay, the positively charged dye penetrates the altered membrane of the microorganism when interacting with a negatively charged material. Positively charged nanoparticles in large quantities around the cell will interfere with the action of the dye; thus, the CFU count method is 
TABLE 6: Recent studies of CeNP antimicrobial activity against Proteus.

\begin{tabular}{|c|c|c|c|c|c|}
\hline Microorganism & Strain of Proteus & $\begin{array}{c}\text { Concentration } \\
(\mathrm{mg} / \mathrm{mL})\end{array}$ & $\begin{array}{l}\text { Microbiological } \\
\text { technique }\end{array}$ & Result & Reference $^{\mathrm{A}}$ \\
\hline \multirow{2}{*}{ Proteus morganii } & \multirow{2}{*}{$\begin{array}{l}\text { Clinical urinary } \\
\text { tract infection }\end{array}$} & 0.05 & Agar diffusion & $11.0 \pm 0.51 \mathrm{~mm}$ & \multirow{2}{*}[35]{} \\
\hline & & - & Microdilution & $\begin{array}{c}\mathrm{MIC}=\mathrm{MBC}= \\
20 \mu \mathrm{g} / \mathrm{mL}\end{array}$ & \\
\hline \multirow{3}{*}{ Proteus vulgaris } & \multirow{3}{*}{$\mathrm{Ni}$} & 1.0 & & $0.0 \mathrm{~mm}$ & \multirow{3}{*}[20]{} \\
\hline & & 5.0 & Agar diffusion & $3.67 \pm 0.33 \mathrm{~mm}$ & \\
\hline & & 10.0 & & $8.33 \pm 0.33 \mathrm{~mm}$ & \\
\hline \multirow{3}{*}{ Proteus vulgaris } & \multirow{3}{*}{$\mathrm{Ni}$} & $10^{*}$ & & $0.0 \mathrm{~mm}$ & \multirow{3}{*}[21]{} \\
\hline & & $50^{*}$ & Agar diffusion & $\sim 3 \mathrm{~mm}$ & \\
\hline & & $100^{*}$ & & $4.67 \mathrm{~mm}$ & \\
\hline Proteus mirabilis & ATCC 12459 & - & Macrodilution & $\begin{array}{c}30 \pm 10 \mu \mathrm{g} / \mathrm{mL} \\
\text { (planktonic culture) } \\
360 \pm 160 \mu \mathrm{g} / \mathrm{mL} \\
\text { (biofilm) }\end{array}$ & {$[34]$} \\
\hline
\end{tabular}

${ }^{*} \mathrm{mg} /$ disc; Ni: not identified in the paper; MIC: minimum inhibitory concentration; MBC: minimum bactericidal concentration; ${ }^{\mathrm{A}}$ reference in chronological order. Source: original source.

TABLE 7: Recent studies of antimicrobial activity of CeNP against Streptococcus pneumoniae.

\begin{tabular}{|c|c|c|c|c|}
\hline $\begin{array}{l}\text { Strain of } S . \\
\text { pneumoniae }\end{array}$ & $\begin{array}{c}\text { Concentration } \\
(\mathrm{mg} / \mathrm{mL})\end{array}$ & $\begin{array}{c}\text { Microbiological } \\
\text { technique }\end{array}$ & Result & Reference $^{\mathrm{A}}$ \\
\hline \multirow{3}{*}{ ni } & 1.0 & & $0.0 \mathrm{~mm}$ & \multirow{3}{*}[20]{} \\
\hline & 5.0 & Agar diffusion & $3.33 \pm 0.33 \mathrm{~mm}$ & \\
\hline & 10.0 & & $10.67 \pm 0.33 \mathrm{~mm}$ & \\
\hline \multirow{3}{*}{ ni } & $10^{*}$ & & $0.0 \mathrm{~mm}$ & \multirow{3}{*}[21]{} \\
\hline & $50^{*}$ & Agar diffusion & $\sim 3.60 \mathrm{~mm}$ & \\
\hline & $100^{*}$ & & $\sim 4.33 \mathrm{~mm}$ & \\
\hline ATCC 25923 & - & Macrodilution & $\begin{array}{c}110 \pm 40 \mu \mathrm{g} / \mathrm{mL} \\
\text { (planktonic culture) } \\
180 \pm 80 \mu \mathrm{g} / \mathrm{mL} \\
\text { (biofilm) }\end{array}$ & {$[34]$} \\
\hline
\end{tabular}

${ }^{*} \mathrm{mg} /$ paper disk; ni: not identified in the paper; ${ }^{\mathrm{A}}$ reference in chronological order. Source: original source.

more consistent for verifying the ability of the cells to form colonies.

For Pseudomonas aeruginosa (Gram-negative), only three studies evaluated its sensitivity to nanoparticles, with MICs of $20 \pm 5 \mu \mathrm{g} / \mathrm{mL}$ and $70 \pm 0.0 \mu \mathrm{g} / \mathrm{mL}$ for planktonic cultures and biofilms, respectively [34]. The formation of an inhibition zone ranged from approximately $3 \mathrm{~mm}$ to $4.67 \mathrm{~mm}$ (Table 4). The results of Ravishankar et al. [30] showed a greater CeNP activity against $P$. aeruginosa in smaller doses when the particles were synthesized by combustion and cerium ammonium nitrate was used as a precursor.

Bacillus subtilis (Gram-positive) was sensitive to CeNP, with an inhibition greater than $50 \%$ observed [23]; however, for the $1 \mathrm{mg} / \mathrm{mL}$ concentration, there was no inhibition zone formation (strain not reported) [20], although the CIM observed by Krishnamoorthy et al. [18] was quite small $(4 \mu \mathrm{g} / \mathrm{mL})$ for the KACC strain 14394 (Table 5). This difference can be attributed to differences in strain, route of synthesis, and the salt precursor used.
The genus Proteus (Gram-negative) was tested in four of the 17 studies analyzed. The formation of a $\sim 3-\mathrm{mm}$ inhibition zone was observed for Proteus vulgaris [20, 21], and the inhibition zone was $11.0 \pm 0.51 \mathrm{~mm}$ for Proteus morganii [35] (Table 6).

Streptococcus pneumoniae (Gram-positive) showed a sensitivity to the CeNP at a concentration of $5 \mathrm{mg} / \mathrm{mL}$ with the formation of a $3.33 \pm 0.33 \mathrm{~mm}$ inhibition zone [20] (Table 7).

Only one study evaluated the sensitivity of C. albicans to CeNP [7] using a clinical strain (UCM Y-690). A CeNP concentration of $0.017 \mathrm{mg} / \mathrm{mL}$ (lowest) yielded a reduction in the viability of the fungus, while a $0.17 \mathrm{mg} / \mathrm{mL}$ concentration caused the complete inhibition of the fungus viability.

An $8 \mu \mathrm{g} / \mathrm{mL}$ MIC of CeNP was observed for Enterococcus faecalis (Gram-positive) (KACC 13807) and for Salmonella typhimurium (KCCM 40253) [18]. In another E. faecalis strain (ATCC 19433), the MIC was $50 \pm 20 \mu \mathrm{g} / \mathrm{mL}$ and $270 \pm$ $0.0 \mu \mathrm{g} / \mathrm{mL}$ for the planktonic culture and biofilm, respectively [34]. Other strains showed different MICs; however, the salt 
precursor was the same, and the synthesis method varied between the studies, with the sonochemical method seeming to be the most effective.

Klebsiella pneumoniae (Gram-negative) (ATCC 13833) presented sensitivity to CeNP (MICs of $140 \pm 0.0$ and $360 \pm 160 \mu \mathrm{g} / \mathrm{mL}$ for planktonic culture and biofilm, resp.) [34]. Arumugam et al. [21] observed inhibition zones of approximately 2.6 and $4.67 \mathrm{~mm}$ at concentrations of 50 and $100 \mathrm{mg} /$ paper disk, respectively. Similar values were found for Shigella dysenteriae (Gram-negative).

The clinical strain urinary tract bacteria Klebsiella sp. $(6.00 \pm 0.74 \mathrm{~mm})$ and Enterobacter sp. $(6.00 \pm 0.12 \mathrm{~mm})$ had the same inhibition zone value [35].

The cerium oxide formed a small inhibition zone $(<3 \mathrm{~mm})$ at a concentration of $10 \mathrm{mg} / \mathrm{mL}$ for Klebsiella aerogenes (Gram-negative) (NCIM-2098) [17, 22]. The nanoparticles produced by Malleshappa et al. [22] were smaller and had a defined shape (cube), while those of Reddy Yadav et al. [17] were larger (when compared with nanoparticles of [22]) with irregular shapes (Table 1).

Shewanella oneidensis MR-1 (Gram-negative) is a facultative bacterium and was not sensitive to CeNP at concentrations of 50 to $150 \mathrm{mg} / \mathrm{mL}$ [11].

Masadeh et al. [34] performed a study aiming to determine the MIC of CeNP against various Gram-positive and Gram-negative bacteria. Below are the sensitivity of the microorganisms tested for the first time in the literature with CeNP in planktonic culture and biofilms, respectively: Acinetobacter baumannii (Gram-negative) ATCC 17978 (70 \pm $0.0 \mu \mathrm{g} / \mathrm{mL}$ and $360 \pm 160 \mu \mathrm{g} / \mathrm{mL})$; Streptococcus pyogenes (Gram-positive) ATCC $19615(30 \pm 10 \mu \mathrm{g} / \mathrm{mL}$ and $70 \pm$ $0.0 \mu \mathrm{g} / \mathrm{mL}$ ); Haemophilus influenzae (Gram-negative) ATCC $29247(360 \pm 160 \mu \mathrm{g} / \mathrm{mL}$ and $530 \pm 0.0 \mu \mathrm{g} / \mathrm{mL})$; Staphylococcus epidermidis (Gram-positive) ATCC $12228(20 \pm 5 \mu \mathrm{g} / \mathrm{mL}$ and $90 \pm 40 \mu \mathrm{g} / \mathrm{mL})$; Enterobacter aerogenes ATCC 29751 $(70 \pm 0.0 \mu \mathrm{g} / \mathrm{mL}$ and $140 \pm 0.0 \mu \mathrm{g} / \mathrm{mL})$; Citrobacter freundii (Gram-negative) ATCC 8090; and Enterobacter cloacae (Gram-negative) ATCC $13047(70 \pm 0.0 \mu \mathrm{g} / \mathrm{mL}$ and $220 \pm$ $80 \mu \mathrm{g} / \mathrm{mL}$ for both bacteria).

Kannan and Sundrarajan [13] suggested that CeNP can be used as an effective inhibitor in antimicrobial control systems. The effectiveness of the nanoparticles depends on their morphology and size. Masadeh et al. [34], after testing various strains of different species of microorganisms, stated that CeNP is not a good antibacterial candidate.

3.3. Cerium Oxide Nanoparticles against Opportunistic Microorganisms: Mechanism of Action. CeNP showed activity in Gram-positive and Gram-negative bacteria, with the greatest antimicrobial activity observed against Gram-negative bacteria (E. coli) [22]. Gram-positive bacteria have a thick layer of peptidoglycan that contains linear polysaccharides chains with short peptides that together form a rigid structure that is difficult to penetrate with CeNP. Gram-negative bacteria have a thin layer of peptidoglycan and a lipopolysaccharide that protects the cytoplasmic membrane from outside chemical agents [22]. Gopinath et al. [20] stressed that the greater antibacterial activity of CeNP on Gram-positive bacteria is possibly because the peptidoglycan layer possesses teichoic acid as interaction site for CeNP. Both studies used the agar diffusion method, which yielded small inhibition halo values at the concentrations tested.

Transmission electron microscopy showed that the cerium oxide nanoparticles with antimicrobial activity against $E$. coli adsorb to the bacteria surface but do not penetrate the cell [11]. These findings are in accordance with Thill et al. [28], who suggested three types of interaction between bacteria and CeNP: (1) adsorption, (2) oxi-reduction, and (3) toxicity.

(1) Adsorption occurs by electrostatic attraction, possibility modifying cellular transport via ionic pumps [28]. Extracellular polymeric substances production by a microorganism, for example, Synechocystis, can compromise adsorption and the consequent oxireduction [29].

(2) In the process of oxi-reduction, modifications occur on the surface of the nanoparticle and the bacteria. The $\mathrm{Ce}^{4+}$ charge of the nanoparticles is reduced to $\mathrm{Ce}^{3+}$ in the presence of the bacteria (E. coli), resulting in oxidative stress on lipids and/or proteins in the plasma membrane of the microorganism, or through cellular metabolism electron uptake. It is important to highlight that no reduction of $\mathrm{Ce}^{4+}$ was observed in abiotic culture medium $[28,29]$.

(3) Toxicity involves the impairment of cellular respiration, as observed by differences in gene expression, in nanoparticulate exposed and nonexposed E. coli. The low level of succinate dehydrogenase and cytochrome $\mathrm{b}$ terminal oxidase gene expression in the experimental group indicates that cerium attacks electron flow and bacterial respiration [11]. With respect to Candida albicans, it is believed that the interaction between cerium and components of the fungal cell wall can cause irreversible changes, such as blocking fungal enzymatic activity [7].

Another relevant factor in antimicrobial activity is altering of nanoparticle surface charge by the culture medium $\mathrm{pH}$. The extreme $\mathrm{pH}$ ranges after the incubation period contribute to this activity by establishing an unfavorable environment for the proliferation by microorganisms [11].

Considering the above factors, a diagram representing the probable mechanism of antimicrobial action for cerium oxide nanoparticles is proposed (Figure 2).

\section{Conclusions}

The reviewed studies report the antimicrobial activity for CeNP as synthesized by different routes that use nitrate or chloride salt precursors and have a size of less than $54 \mathrm{~nm}$. A lack of standardization between the studies, for both the bacteria used and concentrations of CeNP tested, makes them difficult to compare and determine the most efficient synthesis route. Aggregation of CeNP particles by moisture in the air seems to inhibit antimicrobial activity, and it is necessary to standardize the studies with a storage protocol 


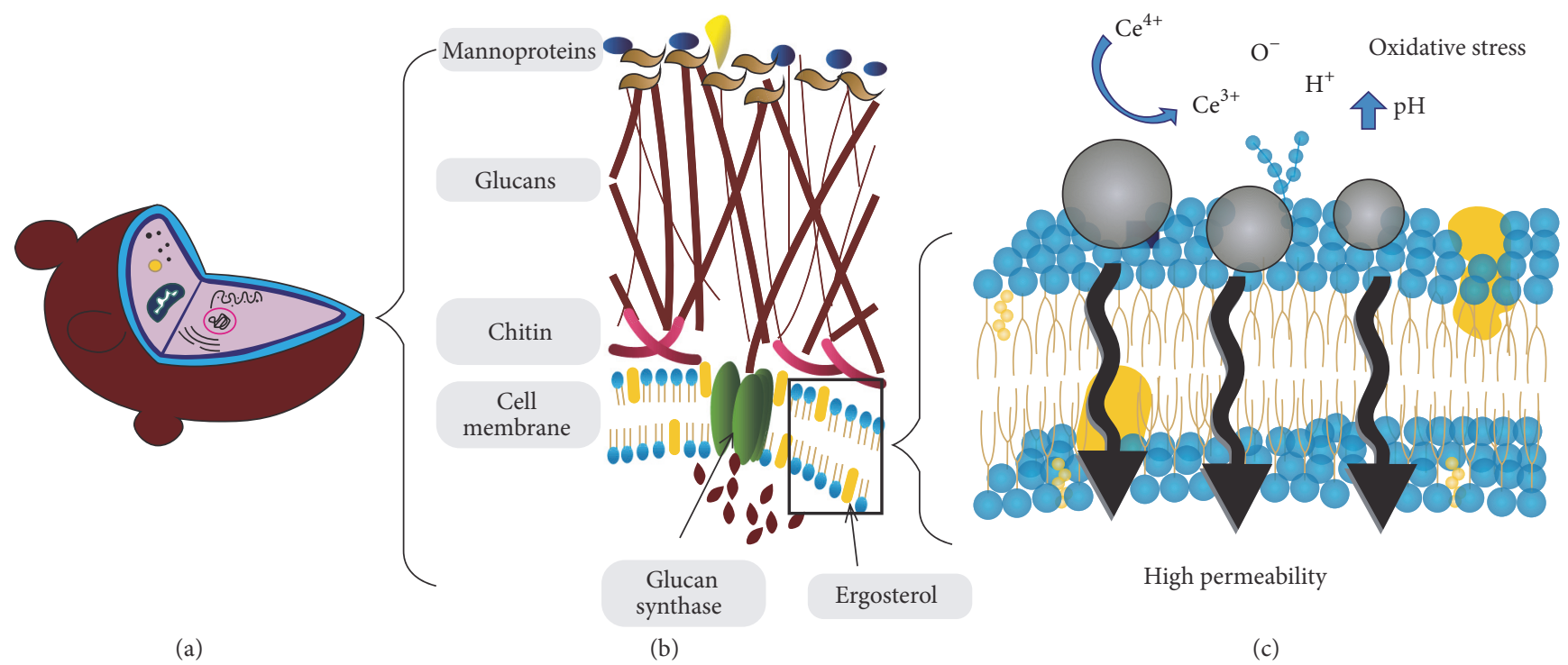

Figure 2: Diagram of the probable mechanism of antimicrobial action for cerium oxide nanoparticulates on the cell membrane. Candida albicans; (b) the cell wall of the fungus formed by monoproteins, insoluble glycan and chitin. Phospholipid bilayer of the cell membrane with glycan synthase and ergosterol. (c) Adsorption of cerium oxide nanoparticles, reduction of $\mathrm{Ce}^{4+}$ to $\mathrm{Ce}^{3+}$, elevation of $\mathrm{pH}$, and oxidative stress of the fungus.

in a dryer, sonicate the nanoparticles, and use Tween-80 surfactant.

The antimicrobial mechanism of action is probably due to oxidative stress on components of the microorganism cell membrane, manly of Gram-negative and fungi microorganisms. This process occurs during CeNP adsorption to the bacterium, which is favored by the acidic $\mathrm{pH}$ of the site of infection, since at a low $\mathrm{pH}$, the nanoparticles become positively charged and more easily adhere to the negatively charged bacteria through electrostatic interactions. During this process, a change in valence on the surface of the cerium oxide nanoparticle occurs by gain of an electron, converting $\mathrm{Ce}^{4+}$ to $\mathrm{Ce}^{3+}$. The greatest antimicrobial activity observed against Gram-negative and fungi occur probably by direct contact and unbalance of the outer membrane. Conversely, in Gram-positive bacteria a thick layer of peptidoglycan in their membrane can modulate this effect. As a result, few particles of $\mathrm{Ce}^{4+}$ are reduced to $\mathrm{Ce}^{3+}$ and the oxidative stress events in Gram-positive bacteria are diminished.

\section{Abbreviations}

CeNPs: Cerium oxide nanoparticles

MRSA: Methicillin-resistant Staphylococcus aureus

SciELO: Scientific Electronic Library Online

Lilacs: Latin American and Caribbean Literature on Health Sciences

BET: Brunauer-Emmett-Teller

DSF: Debye-Scherrer formula

Ni: $\quad$ Not identified

TEM: Transmission electron microscopy

SEM: $\quad$ Scanning microscopy electron

$\mathrm{CFU} / \mathrm{mL}$ : Colony forming unit per milliliter
MIC: $\quad$ Minimum inhibitory concentration

MBC: Minimum bactericidal concentration

E. col: $\quad$ Escherichia coli

P. aeruginosa: Pseudomonas aeruginosa

B. subtilis: Bacillus subtilis

C. albicans: Candida albicans

E. faecalis: Enterococcus faecalis.

\section{Conflicts of Interest}

The authors declare that there are no conflicts of interest regarding the publication of this paper.

\section{References}

[1] D. M. Sievert, P. Ricks, J. R. Edwards et al., "Antimicrobialresistant pathogens associated with healthcare- associated infections: summary of data reported to the national healthcare safety network at the centers for disease control and prevention, 2009-2010," Infection Control and Hospital Epidemiology, vol. 34, no. 1, pp. 1-14, 2013.

[2] H. Wisplinghoff, J. Ebbers, L. Geurtz et al., "Nosocomial bloodstream infections due to Candida spp. in the USA: species distribution, clinical features and antifungal susceptibilities," International Journal of Antimicrobial Agents, vol. 43, no. 1, pp. 78-81, 2014.

[3] J. M. Achkar and B. C. Fries, "Candida infections of the genitourinary tract," Clinical Microbiology Reviews, vol. 23, no. 2, pp. 253-273, 2010.

[4] C. S. Lim, R. Rosli, H. F. Seow, and P. P. Chong, "Candida and invasive candidiasis: back to basics," European Journal of Clinical Microbiology \& Infectious Diseases, vol. 31, no. 1, pp. 2131, 2012. 
[5] L. Zhang, S. Zhou, A. Pan, J. Li, and B. Liu, "Surveillance of antifungal susceptibilities in clinical isolates of Candida species at 36 hospitals in China from 2009 to 2013," International Journal of Infectious Diseases, vol. 33, pp. 1-4, 2015.

[6] N. Sanvicens and M. P. Marco, "Multifunctional nanoparticles-properties and prospects for their use in human medicine," Trends in Biotechnology, vol. 26, no. 8, pp. 425-433, 2008.

[7] L. P. Babenko, N. M. Zholobak, A. B. Shcherbakov, S. I. Voychuk, L. M. Lazarenko, and M. Y. Spivak, "Antibacterial activity of cerium colloids against opportunistic microorganisms in vitro.," Mikrobiolohichnyǐ zhurnal (Kiev, Ukraine : 1993), vol. 74, no. 3, pp. 54-62, 2012.

[8] M. Ramasamy and J. Lee, "Recent nanotechnology approaches for prevention and treatment of biofilm-associated infections on medical devices," BioMed Research International, vol. 2016, Article ID 1851242, 2016.

[9] Z. Liu, J. Liu, R. Wang, Y. Du, J. Ren, and X. Qu, "An efficient nano-based theranostic system for multi-modal imagingguided photothermal sterilization in gastrointestinal tract," Biomaterials, vol. 56, pp. 206-218, 2015.

[10] X. Yang, J. Yang, L. Wang et al., "Pharmaceutical IntermediateModified Gold Nanoparticles: Against Multidrug-Resistant Bacteria and Wound-Healing Application via an Electrospun Scaffold," ACS Nano, vol. 11, no. 6, pp. 5737-5745, 2017.

[11] D. A. Pelletier, A. K. Suresh, G. A. Holton et al., "Effects of engineered cerium oxide nanoparticles on bacterial growth and viability," Applied and Environmental Microbiology, vol. 76, no. 24, pp. 7981-7989, 2010.

[12] A. Bumajdad, J. Eastoe, and A. Mathew, "Cerium oxide nanoparticles prepared in self-assembled systems," Advances in Colloid and Interface Science, vol. 147-148, pp. 56-66, 2009.

[13] S. K. Kannan and M. Sundrarajan, "A Green Approach for the Synthesis of a Cerium Oxide Nanoparticle: Characterization and Antibacterial Activity," International Journal of Nanoscience, vol. 13, no. 03, p. 1450018, 2014.

[14] T. V. Surendra and S. M. Roopan, "Photocatalytic and antibacterial properties of phytosynthesized CeO2 NPs using Moringa oleifera peel extract," Journal of Photochemistry and Photobiology B: Biology, vol. 161, pp. 122-128, 2016.

[15] M. Negahdary, G. Mohseni, M. Fazilati et al., "The Antibacterial effect of cerium oxide nanoparticles on Staphylococcus aureus bacteria," Annals of Biological Research, vol. 3, pp. 3671-3678, 2012.

[16] R. Cuahtecontzi-Delint, M. A. Mendez-Rojas, E. R. Bandala, M. A. Quiroz, S. Recillas, and J. L. Sanchez-Salas, "Enhanced antibacterial activity of $\mathrm{CeO} 2$ nanoparticles by surfactants," International Journal of Chemical Reactor Engineering, vol. 11, no. 2, pp. 781-785, 2013.

[17] L. S. Reddy Yadav, K. Manjunath, B. Archana et al., "Fruit juice extract mediated synthesis of $\mathrm{CeO} 2$ nanoparticles for antibacterial and photocatalytic activities," The European Physical Journal Plus, vol. 131, no. 5, article no. 154, 2016.

[18] K. Krishnamoorthy, M. Veerapandian, L.-H. Zhang, K. Yun, and S. J. Kim, "Surface chemistry of cerium oxide nanocubes: Toxicity against pathogenic bacteria and their mechanistic study," Journal of Industrial and Engineering Chemistry, vol. 20, no. 5, pp. 3513-3517, 2014.

[19] A. Liberati, D. G. Altman, J. Tetzlaff et al., "The PRISMA statement for reporting systematic reviews and meta-analyses of studies that evaluate healthcare interventions: explanation and elaboration," British Medical Journal, vol. 339, Article ID b2700, 2009.

[20] K. Gopinath, V. Karthika, C. Sundaravadivelan, S. Gowri, and A. Arumugam, "Mycogenesis of cerium oxide nanoparticles using Aspergillus niger culture filtrate and their applications for antibacterial and larvicidal activities," Journal of Nanostructure in Chemistry, vol. 5, no. 3, pp. 295-303, 2015.

[21] A. Arumugam, C. Karthikeyan, A. S. Haja Hameed, K. Gopinath, S. Gowri, and V. Karthika, "Synthesis of cerium oxide nanoparticles using Gloriosa superba L. leaf extract and their structural, optical and antibacterial properties," Materials Science and Engineering C: Materials for Biological Applications, vol. 49, pp. 408-415, 2015.

[22] J. Malleshappa, H. Nagabhushana, S. C. Sharma et al., "Leucas aspera mediated multifunctional $\mathrm{CeO}_{2}$ nanoparticles: Structural, photoluminescent, photocatalytic and antibacterial properties," Spectrochimica Acta Part A: Molecular and Biomolecular Spectroscopy, vol. 149, pp. 452-462, 2015.

[23] S. N. Patil, J. S. Paradeshi, P. B. Chaudhari, S. J. Mishra, and B. L. Chaudhari, "Bio-therapeutic Potential and Cytotoxicity Assessment of Pectin-Mediated Synthesized Nanostructured Cerium Oxide," Applied Biochemistry and Biotechnology, vol. 180, no. 4, pp. 638-654, 2016.

[24] European Comission, "Recomendation on the definition of a nanomaterial, 2017," http://ec.europa.eu/environment/ chemicals/nanotech/\#definition.

[25] K. R. Raghupathi, R. T. Koodali, and A. C. Manna, "Sizedependent bacterial growth inhibition and mechanism of antibacterial activity of zinc oxide nanoparticles," Langmuir, vol. 27, no. 7, pp. 4020-4028, 2011.

[26] R. A. Yokel, M. T. Tseng, M. Dan et al., "Biodistribution and biopersistence of ceria engineered nanomaterials: Size dependence," Nanomedicine: Nanotechnology, Biology and Medicine, vol. 9, no. 3, pp. 398-407, 2013.

[27] S. Soren, S. R. Jena, L. Samanta, and P. Parhi, "Antioxidant Potential and Toxicity Study of the Cerium Oxide Nanoparticles Synthesized by Microwave-Mediated Synthesis," Applied Biochemistry and Biotechnology, vol. 177, no. 1, pp. 148-161, 2015.

[28] A. Thill, O. Zeyons, O. Spalla et al., "Cytotoxicity of $\mathrm{CeO}_{2}$ nanoparticles for Escherichia coli. physico-chemical insight of the cytotoxicity mechanism," Environmental Science \& Technology, vol. 40, no. 19, pp. 6151-6156, 2006.

[29] O. Zeyons, A. Thill, F. Chauvat et al., "Direct and indirect $\mathrm{CeO} 2$ nanoparticles toxicity for Escherichia coli and Synechocystis," Nanotoxicology, vol. 3, no. 4, pp. 284-295, 2009.

[30] T. N. Ravishankar, T. Ramakrishnappa, G. Nagaraju, and H. Rajanaika, "Synthesis and characterization of $\mathrm{CeO}_{2}$ nanoparticles via solution combustion method for photocatalytic and antibacterial activity studies," ChemistryOpen, vol. 4, no. 2, pp. 146-154, 2015.

[31] S. M. Hirst, A. S. Karakoti, R. D. Tyler, N. Sriranganathan, S. Seal, and C. M. Reilly, "Anti-inflammatory properties of cerium oxide nanoparticles," Small, vol. 5, no. 24, pp. 2848-2856, 2009.

[32] S. S. Hardas, R. Sultana, G. Warrier et al., "Rat brain pro-oxidant effects of peripherally administered $5 \mathrm{~nm}$ ceria 30 days after exposure," NeuroToxicology, vol. 33, no. 5, pp. 1147-1155, 2012.

[33] G. Pulido-Reyes, I. Rodea-Palomares, S. Das et al., "Untangling the biological effects of cerium oxide nanoparticles: The role of surface valence states," Scientific Reports, vol. 5, Article ID 15613, 2015. 
[34] M. M. Masadeh, G. A. Karasneh, M. A. Al-Akhras et al., "Cerium oxide and iron oxide nanoparticles abolish the antibacterial activity of ciprofloxacin against gram positive and gram negative biofilm bacteria," Cytotechnology, vol. 67, no. 3, pp. 427435, 2015.

[35] S. Ravikumar, R. Gokulakrishnan, and P. Boomi, "In vitro antibacterial activity of the metal oxide nanoparticles against urinary tract infectious bacterial pathogens," Asian Pacific Journal of Tropical Disease, vol. 2, no. 2, pp. 85-89, 2012. 


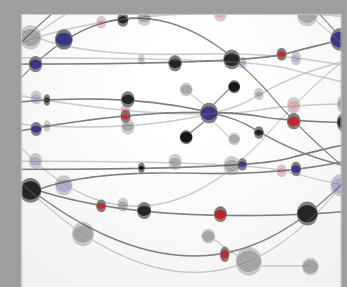

The Scientific World Journal
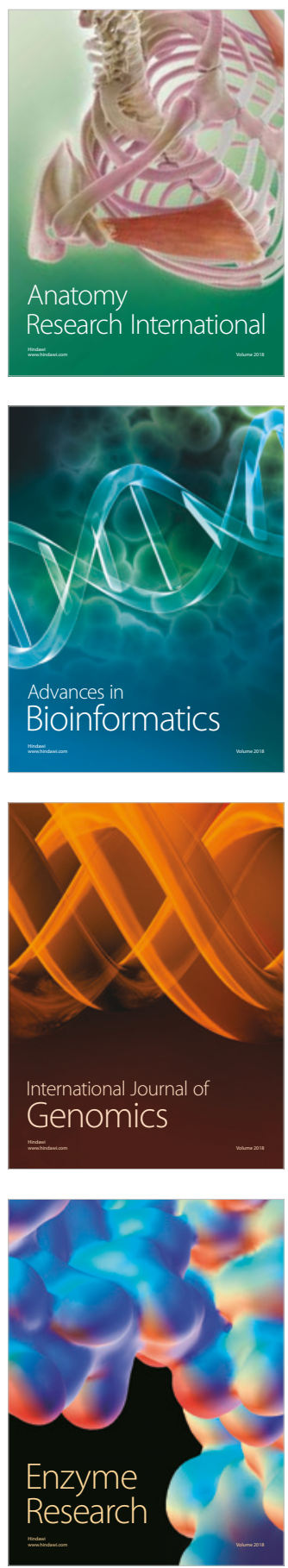
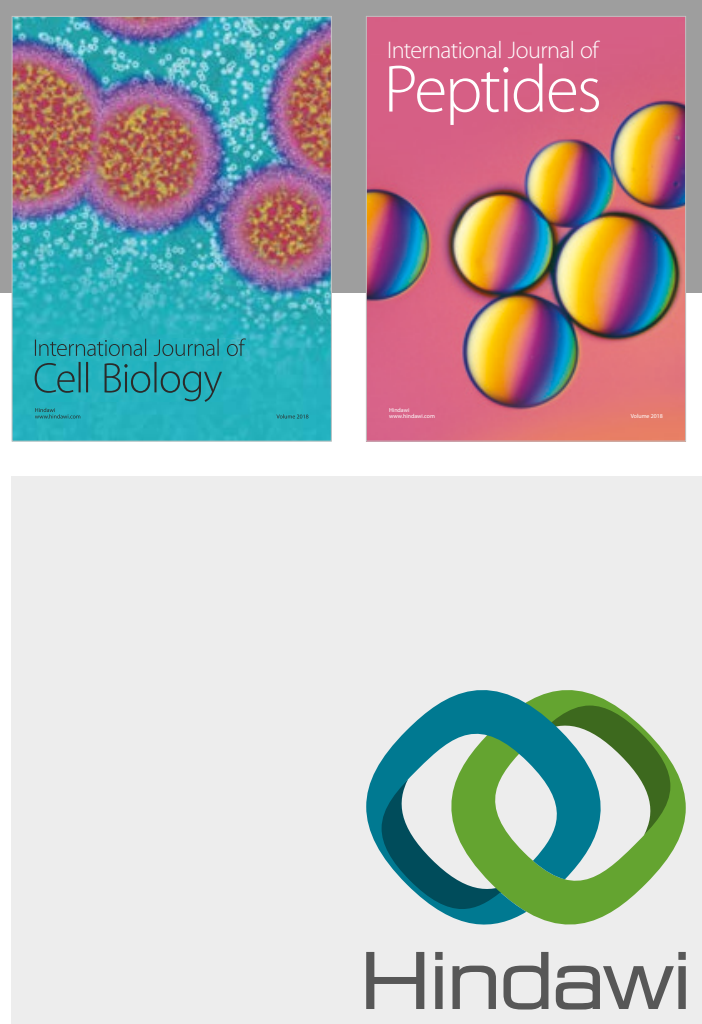

Submit your manuscripts at

www.hindawi.com
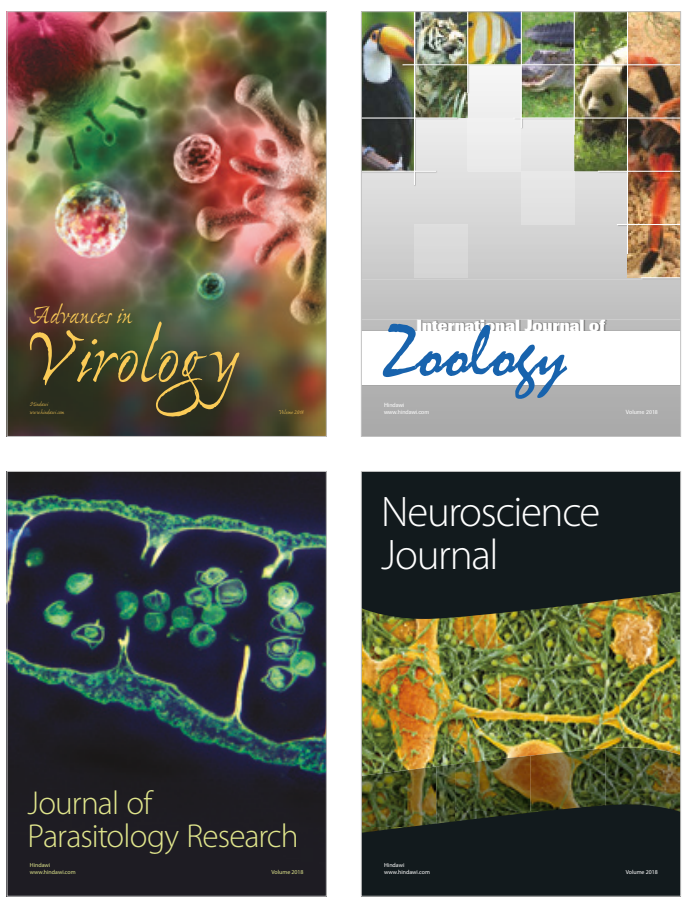
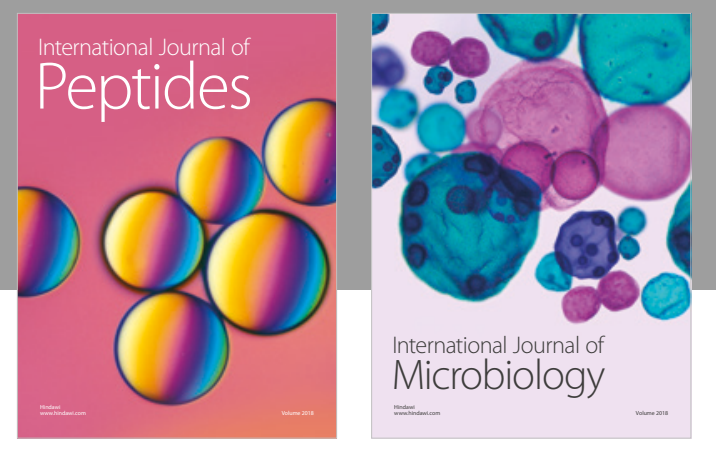

nternational Journal of Microbiology
Journal of
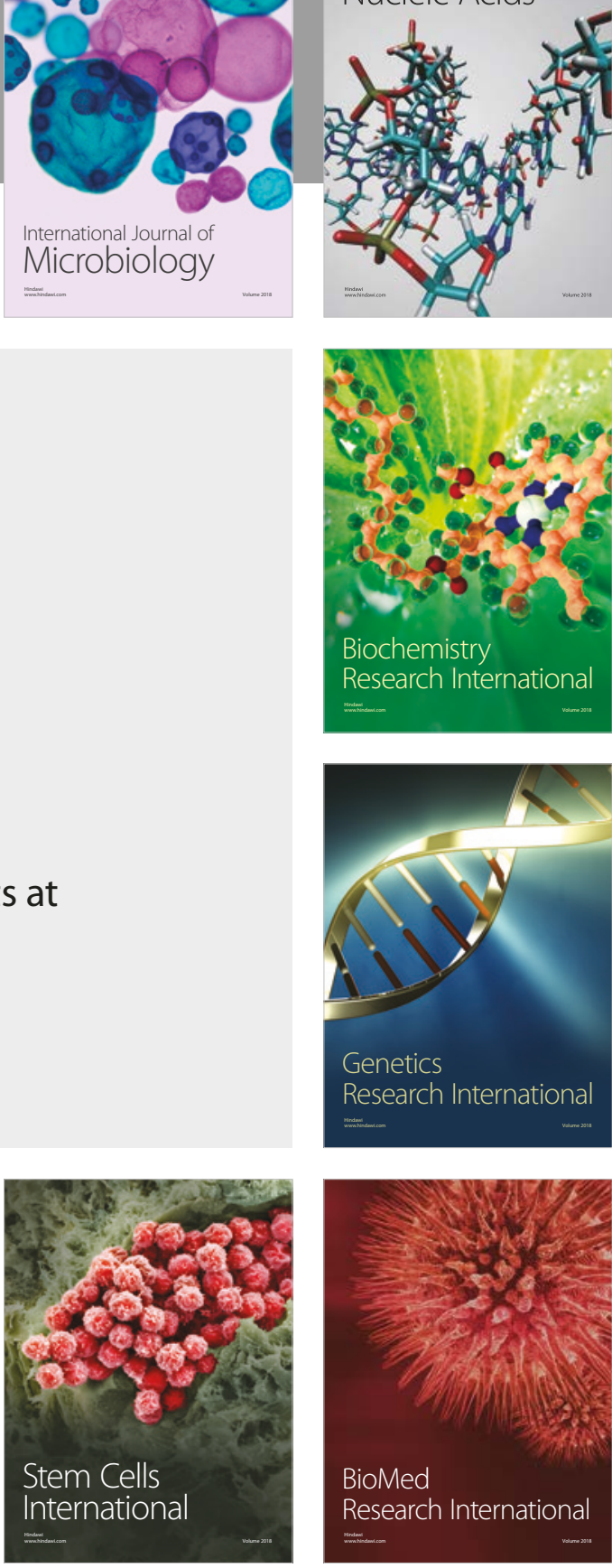
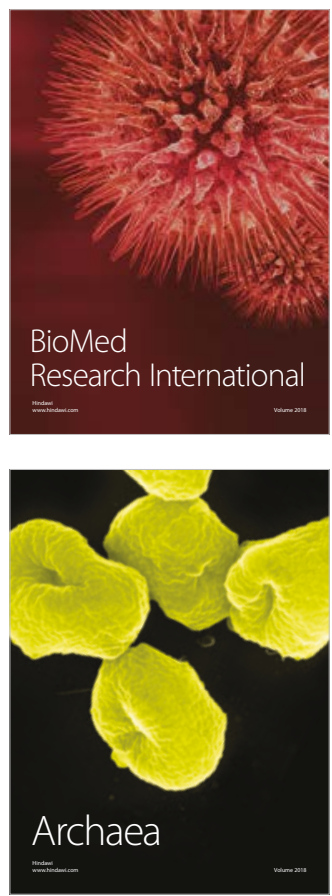